\title{
Technique of spinal cord compression induced by inflation of epidural balloon catheter in rabbits (Oryctologus cuniculus): efficient and easy to use model
}

\author{
ANTONIO F.B. DA FONSECA ${ }^{1}$, JUSSARA P. SCHEFFER ${ }^{1}$, BARBARA P. COELHO ${ }^{2}$, \\ GRACIANE AIELLO ${ }^{3}$, ARTHUR G. GUIMARÃES ${ }^{2}$, CARLOS R.B. GAMA ${ }^{4}$, VICTOR \\ VESCOVINI ${ }^{1}$, PAULA G.A. CABRAL ${ }^{1}$ and ANDRÉ L.A. OLIVEIRA ${ }^{1}$ \\ ${ }^{1}$ Unidade de Experimentação Animal/UEA, Universidade Estadual do Norte Fluminense Darcy Ribeiro/ \\ UENF, Av. Alberto Lamego, 2000, Parque Califórnia, 28013-602 Campos dos Goytacazes, RJ, Brasil \\ ${ }^{2}$ Centro de Biociências e Biotecnologia, Universidade Estadual do Norte Fluminense Darcy Ribeiro/UENF, \\ Av. Alberto Lamego, 2000, Parque Califórnia, 28013-602 Campos dos Goytacazes, RJ, Brasil \\ ${ }^{3}$ Universidade Estadual de Santa Maria, Av. Roraima, 1000, Camobi, 97105-900 Santa Maria, RS, Brasil \\ ${ }^{4}$ Fundação Educacional Serra dos Órgãos, Av. Alberto Torres, 111, Alto, 25964-000 Teresópolis, RJ, Brasil \\ Manuscript received on January 29, 2016; accepted for publication on May 9, 2016
}

\begin{abstract}
The most common cause of spinal cord injury are high impact trauma, which often result in some motor impairment, sensory or autonomic a greater or lesser extent in the distal areas the level of trauma. In terms of survival and complications due to sequelae, veterinary patients have a poor prognosis unfavorable. Therefore justified the study of experimental models of spinal cord injury production that could provide more support to research potential treatments for spinal cord injuries in medicine and veterinary medicine. Preclinical studies of acute spinal cord injury require an experimental animal model easily reproducible. The most common experimental animal model is the rat, and several techniques for producing a spinal cord injury. The objective of this study was to describe and evaluate the effectiveness of acute spinal cord injury production technique through inflation of Fogarty ${ }^{\circledR}$ catheter using rabbits as an experimental model because it is a species that has fewer conclusive publications and contemplating. The main requirements of a model as low cost, handling convenience, reproducibility and uniformity. The technique was adequate for performing preclinical studies in neuro-traumatology area, effectively leading to degeneration and necrosis of the nervous tissue fostering the emergence of acute paraplegia.
\end{abstract}

Key words: experimental, neuro-traumatology, paraplegia, rabbits.

\section{INTRODUCTION}

Spinal cord injuries often result in some motor impairment, sensory or autonomic a greater or lesser extent in the distal areas to the level of trauma. Despite surgical and medical advances are no effective treatments for most patients (Mothe and Tator 2012).

Correspondence to: Jussara Peters Scheffer

E-mail: jussarapeters@yahoo.com.br
In humans, the most common cause of spinal cord injury are high impact from road traffic accidents trauma and some sports activities and most patients are between 10 and 40 years old. The worldwide annual incidence is around 15 to 40 million cases, and the survival rate is high in developed countries, but a considerable number of patients becoming chronic patients with sequelae of spinal cord injury (Sekhon and Fehlings 2001). 
In veterinary medicine there are no national or global statistics about the number of companion animals suffering from spinal cord injury or epidemiological, etiological studies, the incidence and prevalence of cases, however, the most common cause is the same for humans, therefore the trauma, and the age range is also quite wide. In terms of survival and complications due to sequelae, veterinary patients have a worse perspective, either by the delay or lack of adequate veterinary care or the convenience of the owner that can opt for euthanasia.

Thus, justified the study of experimental production models spinal cord injury which may provide more support researches for potential treatments of spinal cord lesions in medicine and veterinary medicine.

The treatment of acute spinal cord injuries usually involve surgical procedures such as decompression, realignment and stabilization of the vertebrae in order to prevent worsening or continuity of the damage to the nervous system.

Preclinical studies of acute spinal cord injury require an experimental animal model easily reproducible, presenting gradable and quantifiable answers reliably. In the last decades, several experimental models of acute spinal cord injury in various animal species have been developed in order to search for effective methods of treatment of such injuries. The most common experimental animal model are rats because of their lower cost of acquisition, maintenance and simple management, and also easy monitoring of physiological parameters.

The most common techniques to produce spinal cord injury are those using weight pendulums (Behrmann et al. 1992, Gale et al. 1985, Gruner 1992, Wrathall et al. 1985), electromagnetic devices (Behrmann et al. 1992, Hiruma et al. 1999), the technique of "blocking-weight" (Holtz et al. 1990, Li et al. 1996, Nistron and Berglund 1988) and modified aneurysm clip (Rivlin and Tator 1978, Von Euler et al. 1997).
Tarlov et al. (1953) was the first to describe the spinal cord injury technique by extradural balloon inflation in dogs (Tarlov et al. 1953); It has since been used in monkeys (Tator and Deecke 1973), cats (Martin et al. 1992), ferrets (Eidelberg et al. 1976) and rats (Khan and Griebel 1983). These latter authors also concluded that the extent of injury caused spinal cord is a dose-response relationship where the variables are time and volume of inflation/hemorrhage.

Primarily the trauma of the spinal cord injury causes edema, vasospasm, necrosis and then a cascade of patho-physiologic events are triggered and may include: ischemia, apoptosis, electrolyte imbalance, lipid peroxidation with the formation of free radicals and inflammatory response resulting in increased vascular damage.

According to the table of the American Spinal Injury Association (ASIA), spinal cord injury can be classified (A) to (E), wherein (A) represents the motor and sensory complete lesion; (B) motor complete injury and incomplete sensitive; (C) Functional motor incomplete injury; (D) injury incomplete and nonfunctional motor (E) with sensory and motor functions preserved. The presence of sacral sensitivity, distal motor function and sensory motor evoked potential indicate incomplete injury. Have complete injuries are those in which there is no neurological function distal to injury.

Therefore the goal of this study was to describe and evaluate the effectiveness of acute spinal cord injury production technique through Fogarty ${ }^{\circledR}$ catheter inflation using rabbits as a model experimental because it is a species that has fewer conclusive publications and contemplating the main requirements of a model as, low cost, management convenience, reproducibility and uniformity.

\section{MATERIALS AND METHODS}

60 rabbits were used (Oryctolagus cuniculus) adult, female, New Zealand race. To minimize variability 
in the size of the spinal canal, we use only animals with an average weight of $3.0 \mathrm{~kg}$. The animals were kept in the Animal Experimentation Unit of the Universidade Estadual do Norte Fluminense Darcy Ribeiro to the health conditions recommended by the Board of Animal Experimentation. Evaluated the general health of each animal through clinical and laboratory tests (complete blood count and serum chemistry) in order to detect significant organic changes capable of interfering with the results of the study, being used only completely healthy animals.

After induction with midazolam $\left(2 \mathrm{mg} \cdot \mathrm{kg}^{-1}\right)$ associated with ketamine hydrochloride (20 mg.kg${ }^{1}$ ), administered by intramuscular injection, there was a trichotomy of thoraco lumbar region. The intra-operative fluid therapy was performed with Ringer's lactate solution via the marginal vein of the left ear. The induction and maintenance of anesthesia were conducted through face mask in semi open circuit with isoflurane steaming in $100 \%$ oxygen at $2 \mathrm{l} / \mathrm{min}$. The heart and respiratory parameters were monitored throughout the surgical procedure. We used the dorsal laminectomy technique, with the animals placed in sternal position, to access the spinal cord to allow good visualization of the medullary canal (figure 1), and easy introduction of a Fogarty catheter 4F (Edwards ${ }^{\circledR}$ ) (figure 2). To confirm the correct placement of the catheter, there was computed tomography (figures 3 and 4). The dorsal laminectomy is the careful removal of dorsal spinous process, portions of the blades and pedicles to expose the dorsal surface of the spinal cord and nerve roots, with the aid of a dental drill tungsten carbide 8 coupled to a micromotor suspension. In this study, the technique was carried out between

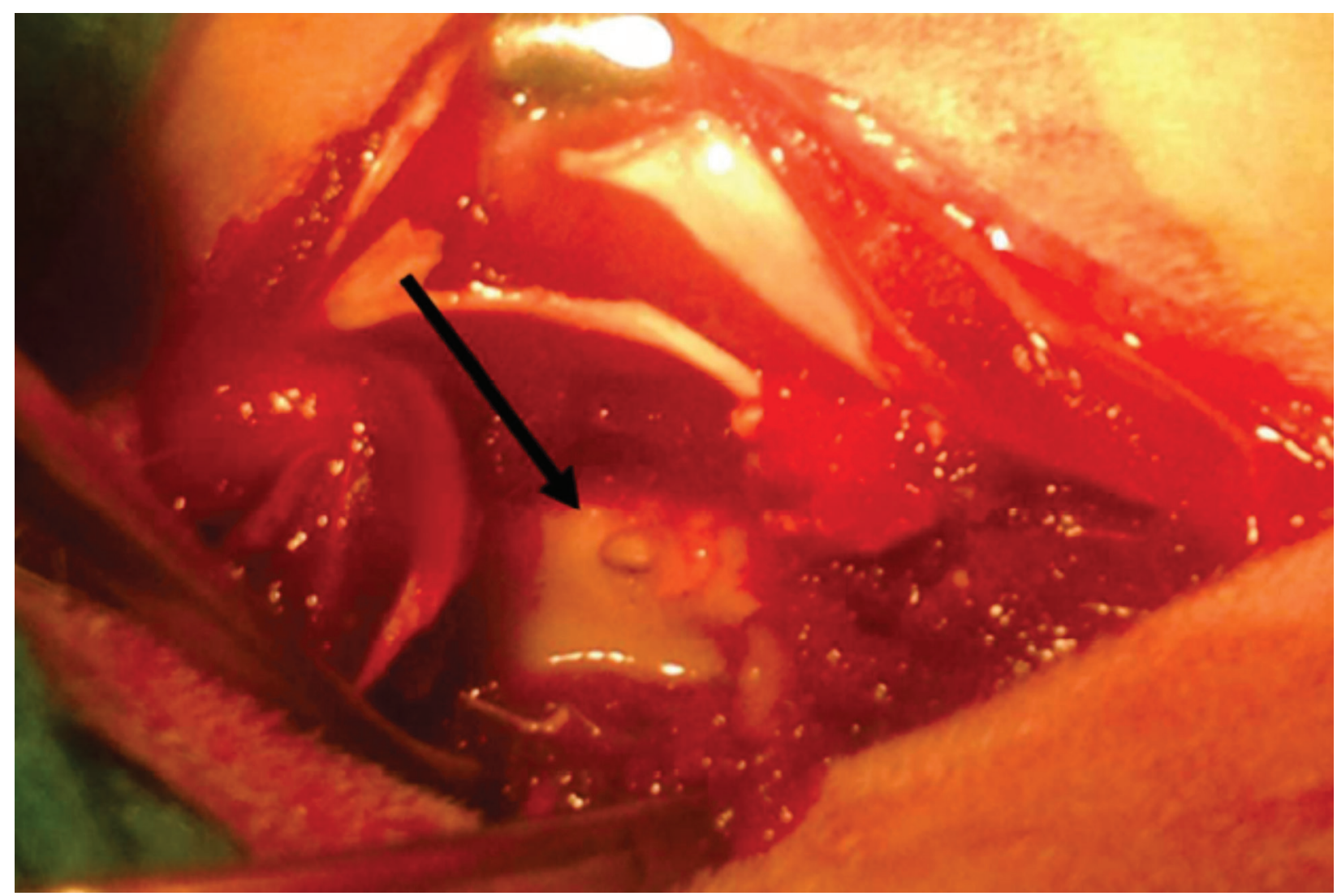

Figure 1 - Image after the completion of the dorsal laminectomy for accessing the spinal canal and visualization of the spinal cord (black arrow). Source: personal archive, 2014. 


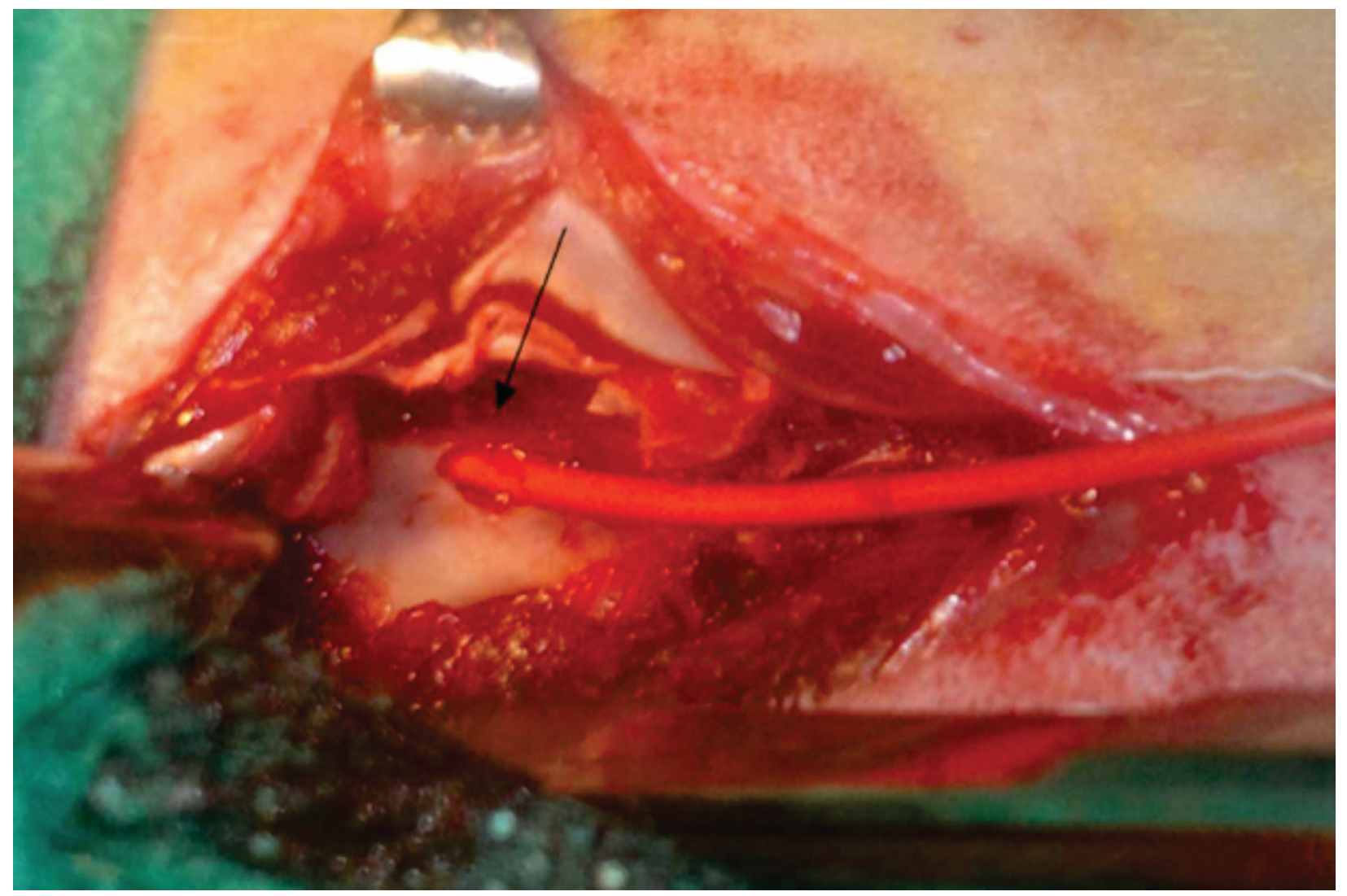

Figure 2 - Introduction of the Fogarty catheter 4F (Edwards ${ }^{\circledR)}$ and post insufflations (black arrow). Source: personal archive, 2014.

the vertebrae L2 and L4, and removing the dorsal spinous processes of L3, where the catheter slowly and dorsal to the spinal cord was introduced until the height of the T13 vertebra. Using 1 cubic centimeters of air to inflate the balloon and remained inflated for ten minutes, after which time there was the removal of the catheter and closing the access site.

Following recovery from anesthesia the animals were evaluated again as to the neurological condition in order to assess the effectiveness of the technique to generate spinal cord injury. All animals received antibiotic therapy with the administration by intramuscular dose of enrofloxacin in 5 mg. $\mathrm{kg}^{-1}$ during 7 days and morphine hydrochloride as pain medication in a dose of $1 \mathrm{mg} \cdot \mathrm{kg}^{-1}$, each 8 hours for 4 days.

The animals were maintained for 4 weeks and then euthanized in accordance with the ethical standards of the Council of animal experimentation. This experiment was approved by the Ethics Committee of Animal Use at the Universidade Estadual do Norte Fluminense under No. 179/2013.

\section{RESULTS AND DISCUSSION}

Spinal cord tissue samples were subjected to histopathological analysis to evaluate changes caused by application of the technique and the same revealed a degeneration of valerian type with necrosis of the posterior spinal area of injury in all cases fairly evenly.

This experimental model was able to accurately reproduce acute spinal cord injury of the compression type, since all the animals being clinically evaluated on each post operative week have presented sensory, motor and autonomic losses. In the evaluation, $84.7 \%$ had complete paraplegia, $15.3 \%$ incomplete paraplegia. 


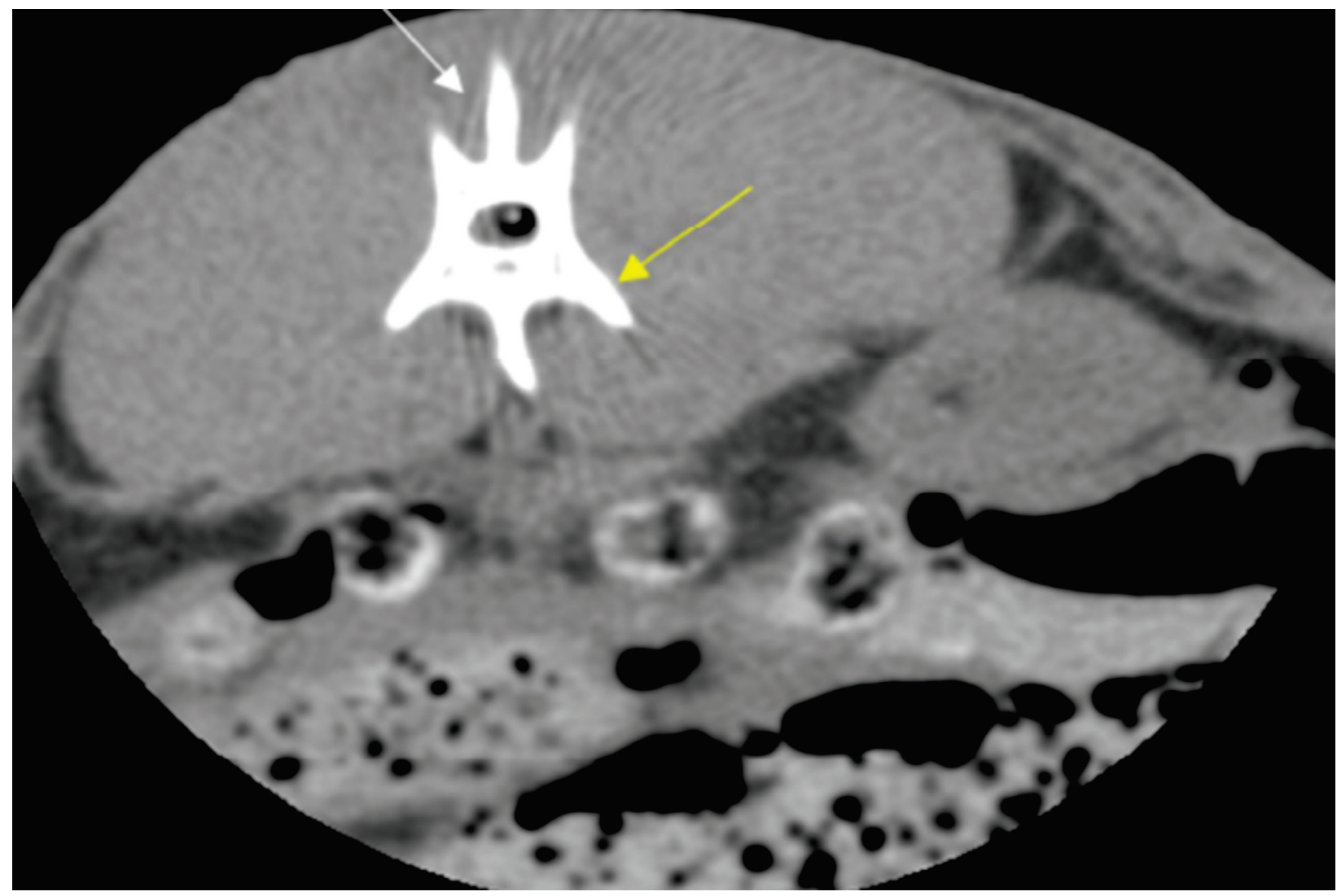

Figure 3 - Tomographic image showing the catheter's placement. Thoracic vertebra T13, spinal process (white arrow), transverse process (yellow arrow). Source: personal archive, 2014.

Practicality, repeatability of results, low cost and quick learning are the adjectives for the technique, but one of the most critical moments that highlights the performance of the procedure is exactly the time insertion of a Fogarty catheter into the spinal canal and displacement along and on the spinal cord, it is necessary to avoid bleeding and mainly positioning this in more thoracic portions, which can promote sleep apnea in the inflation of the cuff and compression of nerve roots related to diaphragm's functioning, corroborating the findings of Lim et al. (2007).

In other works like Kouyoumdjian et al. (2009), we observed proportionally lower insufflation times compared to the one used in this experiment when compared to smaller laboratory species such as mice, so it was necessary to perform the realization of growing inflation times experiment tin order to obtain a degree of compression where all animals presented paraplegia immediately after anesthetic recovery, which occurred inconsistently with shorter times to ten minutes.

The bladder atony sometimes accompanied by hematuria was the most severe clinical signs found in paraplegic animals, causing urinary complications which evolved to death in $4.4 \%$ of the cases, different from the findings of Kouyoumdjian et al. (2009) who did not observe any cases of urinary complications in 76 animals studied.

All animals showed severe atrophy of the posterior muscle groups in the lumbosacral region. Self-mutilation due to sensory loss, neuritis and allodynia was little observed unlike the reports of other authors such as Levit (1985) and Decosterd and Clifford (2000). The post operative period demanded special attention, not only with due to self- 


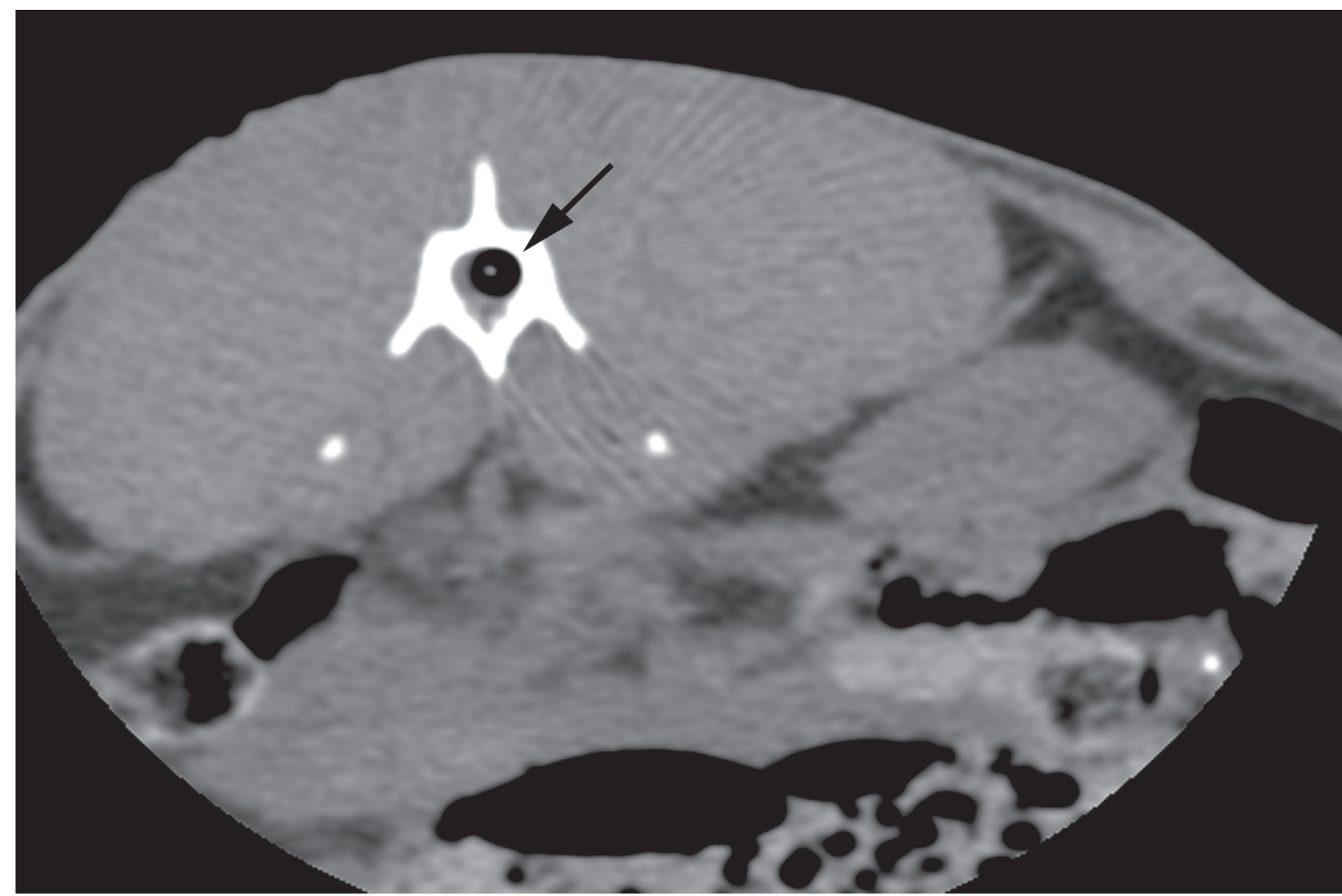

Figure 4 - Tomographic image showing catheter positioning. Spinal canal with the presence of the inflated cuff (white arrow) Source: Personal archive, 2014.

mutilation but also regarding the decubitus sores since the animals were kept for long periods in one position inside the cages, which in this experiment lasted for 30 days post surgery. However, maintaining comfort and survival of these animals was ensured with more intensive nursing attention.

The clinical signs of paralysis, loss of sensorimotor response, muscle atrophy, bladder emptying changes, among others seen in videos recorded once per week for 4 weeks of each animal, characterized compressive spinal cord injury which reinforces the effectiveness of the technique described in this paper.

\section{CONCLUSIONS}

The experimental model of spinal cord injury induced by Fogarty catheter insufflation in the spinal canal of rabbits was adequate to perform preclinical studies in neural trauma area. The inflicted compression caused in the lumbar region of the spinal cord induced effectively degeneration and necrosis of the nervous tissue fostering the emergence of acute paraplegia.

\section{REFERENCES}

BEHRMANN DL ET AL. 1992. Spinal cord Injury produced by consistent mechanical displacement of the cord in rats: behavioral and histologic analysis. J Neurotrauma 9: 197217.

DECOSTERD I AND CLIFFORD JW. 2000. Spared nerve injury: an animal model of persistent peripheral neuropathic pain. Pain 87: 149-158.

EIDELBERG E ET AL. 1979. A model pf spinal cord injury. Surg Neurol 6: 35-38.

GALE K ET AL. 1985. Spinal cord contusion in the rat: behavioral analysis of functional neurologic impairment. Exp Neurol 88: 123-134.

GRUNER JA. 1992. A monitored contusion model of spinal cord injury in the rat. J Neurotrauma 9: 123-126. 
HIRUMA S ET AL. 1999. Simple and reproducible model of rat spinal cord injury induced by a controlled cortical impact device. Neurol Res 21: 313-323.

HOLTZ A ET AL. 1990. Relation between spinal cord blood flow and functional discovery after blocking weightinduced spinal cord injury in rats. Neurosurgery 26: 952957.

KHAN M AND GRIEBEL R. 1983. Acute spinal cord injury in rats: comparison of three experimental techniques. 1983. J Vet Sci 10: 161-165.

KOUYOUMDJIAN PP ET AL. 2009. A remotely controlled model of spinal cord compression injury in mice: toward real-time analysis laboratory investigation. J Neurosurg 11: 461-470.

LEVITT M. 1985. Dysesthesias and self-mutilation in humans and subhumans: A review of clinical and experimental studies. Brain Research 10: 247-290.

LI GL ET AL. 1996. Apoptosis and expression of Bcl-2 after compression trauma to rat spinal cord. J Neuropathol Exp Neurol 55: 280-289.

LIM J ET AL. 2007. Estabilishment of a canine spinal cord injury model induced by epidural balloon compression. J Vet Sci 8: 89-94.

MARTIN D ET AL. 1992. Experimental acute traumatic injury of the adult rats spinal cord by a subdural inflatable balloon: methodology, behavioral analysis, and histophatology. J Neurosci Res 32: 539-550.

MOTHE AJ AND TATOR CH. 2012. Advances in stem cell therapy for spinal cord injury. Clin Invest 122: 3824-3834.

NISTRON B AND BERGLUND JE. 1988. Spinal cord restituti on following compression injuries in rats. Acta Neurol Scand 78: 467-472.

RIVLIN AS AND TATOR CH. 1978. Effect of duration of acute spinal cord injury model in the rat. Surg Neurol 10: $38-43$.

SEKHON LHS AND FEHLINGS MG. 2001. Epidemiology, demographics, and pathophisiology acute spinal cord injury. Spine 26: 2-12.

TARLOV IM ET AL. 1953. Spinal cord compression studies. I. Experimental techniques to produce acute and gradual compression. Arch Neurol Psychiatry 70: 813-819.

TATOR CH AND DEECKE L. 1973. Value of normothermic perfusion, and durotomy in the treatment of experimental acute spinal cord trauma. J Neurosurg 39: 52-64.

VON EULER M ET AL. 1997. Clip compression injury in the spinal cord: a correlative study of neurological and morphological alterations. Exp Neurol 145: 502-510.

WRATHALL JR ET AL. 1985. Spinal cord contusion in the rat: production of graded, reproducible, injury groups. Exp Neurol 88: 108-122. 